\title{
EFECTO DE INCLUSIÓN DE ANTICOAGULANTES DURANTE EL BENEFICIO DE Hevea brasiliensis (Willd. ex A.Juss.) Müll.Arg.
}

\author{
Effect of inclusion of anticoagulants during the benefit \\ of Hevea brasiliensis (Willd. ex A.Juss.) Müll. Arg.
}

\section{Lina Paola Mendoza-Vargas¹ \& Javier Alexander Jiménez-Forero²}

Mendoza-Vargas, L.P., \& Jiménez-Forero, J.A. (2018). Efecto de inclusión de anticoagulantes durante el beneficio de Hevea brasiliensis (Willd. ex A.Juss.) Müll.Arg. Colombia Forestal, 21(1), 91-101

Recepción: 10 de mayo de 2017

\section{Resumen}

Se evaluó el efecto de un agente anticoagulante del látex en el árbol de caucho (Hevea brasiliensis). Se caracterizó el contenido de solidos totales (TSC) y contenido de caucho seco (DRC) del látex, se evaluaron cuatro tratamientos de anticoagulantes en campo: (T1) amoniaco, (T2) bórax, (T3) amoniaco-bórax y (T0) sin anticoagulante. En las láminas se evaluaron cinco diluciones $(\mathrm{v} / \mathrm{v})$ de látex en agua D1 (100\%), D2 (75 \%), D3 (50\%), D4 (25\%) y D5 $(0 \%)$, a estas se hicieron pruebas de tensión, compresión y espesor. El látex caracterizado obtuvo TSC (37.1\% $\% 0.27)$, DRC (34.3\% $\% 0.19)$. Encontrándose en T3D1 mayor resistencia de tensión hasta punto de ruptura de $13.37 \mathrm{KgF}$, compresión de $5 \mathrm{KgF}$, y menor espesor de $1.52 \mathrm{~mm}$, sin diferencia significativa entre los tratamientos T3 y T2 y las diluciones D1 a D2, posibilitando reducir el consumo de agua (25\%), y la producción de ripio (38\%) con anticoagulantes, sin afectar negativamente sus propiedades mecánicas.

Palabras clave: compresión, diluciones, espesor, látex, ripio, tensión.
Aceptación: 28 de agosto de 2017

\begin{abstract}
The effect of the inclusion in the field of an anticoagulant agent in the latex of the rubber tree (Hevea brasiliensis) was evaluated. The content of latex total solids (TSC) and dry rubber content (DRC) were characterized. Four treatments of anticoagulants were evaluated in the field: (T1) ammonia, (T2) borax, (T3) ammonia-borax, and (T0) without anticoagulant. Five dilutions $(\mathrm{v} / \mathrm{v})$ of the latex in water were evaluated in the rubber sheets, D1 (100\%), D2 (75\%), D3 (50\%), D4 (25\%) and D5 (0\%). The obtained sheets were analyzed with tension, compression and thickness tests. The latex had a TSC of $37.1 \%( \pm 0.27)$, and a DRC of $34.3 \%( \pm 0.19)$. We found in T3D1 higher tensile strength up to breaking point of $13.37 \mathrm{KgF}$, compression of $5 \mathrm{KgF}$, and lower thickness of 1.52 $\mathrm{mm}$, without significant differences between treatments $\mathrm{T} 3$ and $\mathrm{T} 2$ and dilutions D1 a D2, enabling to reduce the water consumption (25\%), and the production of gravel (38\%) with anticoagulants, without negatively affecting its mechanical properties.
\end{abstract}

Key words: compression, thickness, dilutions, latex, ripio, tension.

Universidad de los Llanos. Villavicencio, Colombia. Lina.mendoza@unillanos.edu.co. Autor para correspondencia.

Universidad de los Llanos.Villavicencio, Colombia. Jajimenez@unillanos.edu.co 


\section{INTRODUCCIÓN}

El caucho natural es un producto que se obtiene por medio de la sangría de los vasos laticíferos presentes en diversas plantas. En Colombia se explota de manera comercial del árbol del caucho Hevea Brasiliensis (Willd. ex A.Juss.) Müll.Arg. (Quesada et al. ,2012; Departamento Nacional de Planeación, 2007) el látex extraído es una suspensión coloidal compuesta principalmente por agua (52-70 \%) y el hidrocarburo conocido como elastómero o caucho natural (poli [cis-1,4-isopreno]) (27-45\%). Además, tiene otros componentes denominados constituyentes no caucho como ceniza, proteína, resina y azucares (3-6 \%) (Cáceres \& Gauthler, 2012; Camacho et al., 2014), su coloración es blanca, este se encuentra estabilizado por aniones carboxílicos adsorbidos en la superficie formados a partir de ácidos grados y/o proteínas, los cuales ceden carga eléctrica negativa produciendo fuerzas de repulsión que impide la agregación de partículas, es decir, su coagulación.

Sin embargo, la acción bioquímica de enzimas y bacterias presentes naturalmente en la corteza después de la sangría producen la desestabilización de proteinas y fosfolipidos por acidificación del medio, bajando el $\mathrm{pH}$ hasta llegar al punto isoeléctrico donde se anula la carga, lo que disminuye las repulsiones electrostáticas entre las partículas produciendo la coagulación natural espontanea (Nawamawat et al., 2011). Es por ello que, una vez finalizada la sangría, se procede a recolectar el látex en el menor tiempo posible para transportarlo hacia el beneficiadero, buscando evitar la formación de ripio y el espesamiento del látex indeseado por los productores de látex preservado y caucho en láminas, siendo importante el contenido de caucho seco (DRC) y contenido de solidos totales (TSC), para lo cual corrigen el espesamiento con la adición de agua para disminuir la concentración del hidrocarburo. Este consumo de agua es adicional a la utilizada durante la etapa de dilución en proporción 1:1 antes de la acidificación; es decir, por cada litro de látex procesado se adiciona un litro de agua para facilitar la formación del coagulo de laminación y disminuir el contenido de material no caucho en la lámina final, lo cual es una problemática ambiental y economica para el sector (Camacho et al., 2014; Confederación Cauchera Colombiana, 2015a; Zuhainis et al., 2015).

El DRC y el TSC son pruebas de caracterización fisicoquímicas de calidad realizadas al látex, indicadores de parámetro para el proceso de aprovechamiento ya que a partir de este se determina la cantidad de caucho que se obtiene de una muestra de látex (George et al., 2013; Quesada et al., 2014). Las propiedades mecánicas son cualidades importantes del caucho, el esfuerzo de deformación que se ejerce sobre este se presenta con fuerzas externas que se dirigen hacia el centro como lo es la compresión; mientras que en la tensión las fuerzas van hacia afuera hasta llegar al punto de ruptura del material. Estas propiedades se pueden ver afectas al adicionar agentes químicos durante el proceso de transformación como $\mathrm{KOH}$ utilizado para la eliminación de las proteínas (Rayas et al., 2003; Peláez et al., 2014).

La inducción de coagulación deliberada con la adición de agentes coagulantes, como el ácido fórmico o ácido acético, permite procesar el látex en diferentes presentaciones, ya sea como caucho seco en láminas de caucho secadas al aire, láminas de crepé, caucho técnicamente especificado (TSR) y ripio de bajo valor comercial para elaboración de productos como llantas, bolsas, suelas de zapato, partes de equipos plásticas, entre otros. La adición de anticoagulantes no es un proceso nuevo, este proceso se le conoce como tapping, usualmente se adiciona amoníaco en las tazas de recolección del látex, ya que evita la coagulación y es bactericida, muy utilizado para la producción de látex preservado, centrifugado y cremado, utilizado en la fabricación de globos, guantes, condones, moldes entre otros (Camacho et al., 2014; Floriano et al., 2014; Tamara et al., 2015).

A nivel nacional, para el año 2014 se reportaron 50225.1 ha de caucho de las cuales 3178.1 
ha se encontraban en producción y 47047.1 ha se encontraban en sostenimiento. Adicional a esto, 20505.6 ha $(41 \%)$ son de pequeños productores, 13914.7 ha $(28 \%)$ de medianos productores $y$ 15889.5 ha $(31 \%)$ de grandes productores. Sin embargo, existen 5791 pequeños productores que representan el $98.1 \%, 104$ medianos productores que representan el $1.8 \%$ y 8 grandes productores que presentan el $0.1 \%$ de los productores a nivel nacional, repartidos en 17 departamentos. Esta producción representaba 3549.9 t de coágulos de campo que equivalen a 2084.8 t de caucho seco, 379332 I de látex preservado que equivalen a 125.2 t de caucho seco, 570.6 t de lámina y 251 t de subproducto de fondo de taza, ripio y orejas que equivalen a 95.3 t de caucho seco; produciéndose en total 2924.5 t de caucho seco (Confederación Cauchera Colombiana, 2015b). En el departamento del Meta en el mismo año se reportó 17801.4 ha $(35 \%)$ del reporte nacional, de las cuales 892 ha estaban en producción y 10909.1 ha estaban en sostenimiento; 1897.3 ha son de pequeños productores $(10.6 \%), 7660$ ha de medianos productores $(43 \%)$ y 8244.1 ha de grandes productores $(46.3 \%)$; se estaba produciendo 321.1 t de coagulo de campo que equivalen a $186.2 \mathrm{t}$ de caucho seco, 60930 I de látex preservado que equivalen a 20.1 t de caucho seco; 41 t de lámina, 21.7 t en subproductos de fondo de taza, ripio y orejas que equivalen a 12.6 t de caucho seco, produciéndose en total 259.9 t de caucho seco, aportando el $8.8 \%$ de la producción nacional (Confederación Cauchera Colombiana, 2015a).

En el contexto anterior, el objetivo de este trabajo consistió en determinar el efecto de la inclusión en campo de un agente anticoagulante en el espesor final de las láminas de caucho y sus propiedades mecánicas de tensión y compresión, además de la variación del porcentaje de dilución en agua durante el proceso de laminación, observándose adicionalmente el efecto en la formación de subproducto de campo como fondo de taza y ripio.

\section{MATERIALES Y MÉTODOS}

\section{Área de estudio}

Se muestreó y seleccionó aleatoriamente látex del árbol de caucho (Hevea Brasiliensis) Clon FX3864 de seis meses de explotación con frecuencia de rayado de cada cuatro días, procedentes de un cultivo establecido en la finca Palmarito, vereda Quinquita del municipio de Paratebueno (Cundinamarca) Colombia, ubicada a $256 \mathrm{~m}$ de altitud, entre las coordenadas $4^{\circ} 38^{\prime} 85.70^{\prime \prime}$ latitud norte $-73^{\circ} 20^{\prime} 92.85^{\prime \prime}$ longitud oeste, humedad relativa promedio de $75 \%, 3900 \mathrm{~mm}$ precipitaciones anuales, temperatura promedio de $27^{\circ} \mathrm{C}$ y clima tropical.

\section{Análisis de contenido de caucho seco (DRC) y contenido de solidos totales (TSC)}

La caracterización se realizó con los parámetros establecidos en la norma ASTM D1076-88 (Cornish et al., 1988). Finalizado el proceso de sangría se tomó una muestra de látex y se preservó con amoníaco al $5 \%$ v/v. Para el análisis de DRC se obtuvo pesando $10 \mathrm{~g}$ de látex al que se adicionó solución de ácido fórmico al 5 \% v/v hasta obtener coagulación, luego se laminó y se secó a $55^{\circ} \mathrm{C}$ hasta peso constante en un horno de convección natural. Luego, se calculó mediante la siguiente expresión:

$$
\text { DRC \% }=\frac{B}{A} X 100 \quad \text { ecuación } 1
$$

Donde:

DRC: contenido de caucho seco.

A: peso de la muestra inicial.

B: peso del coagulo seco.

Para el TSC se pesaron 2.5 g de látex en una caja Petri y se secaron a $100^{\circ} \mathrm{C}$ hasta obtener peso constante en horno de convección natural, luego se utilizó la siguiente expresión.

$$
T S C=\frac{C-A}{B-A} \quad \text { ecuación } 2
$$


Donde:

TSC: contenido de solidos totales.

A: peso inicial de la caja Petri.

B: peso caja Petri más muestra de látex inicial.

C: peso caja Petri más muestra seca.

Cada ensayo se realizó por quintuplicado.

\section{Anticoagulación en campo}

El tamaño de muestra para la aplicación de los tratamientos de anticoagulación se definió con el 10 \% de los árboles en producción. Se evaluaron cuatro tratamientos de anticoagulación: amoníaco (5 \% v/v) (T1), bórax (4\% g/l) (T2), combinado amoníaco (5\% v/v)-bórax (4\% g/l) (T3), y el testigo sin preservación (T0), con tiempo de sangría de $2 \mathrm{~h}, 2 \mathrm{~cm}^{3}$ de cada tratamiento se aplicaron por aspersión antes de iniciar el proceso de rayado del árbol para la sangría del látex en taza. El ripio formado en las tazas después de la sangría se recolectó y se pesó; se registró la densidad con el instrumento hydrometer low S.T. de la marca Brixco Germany y el pH con el instrumento $\mathrm{pH}$ Metro digital, de la marca Sciennovo Instruments, a cada tratamiento tres horas después del inicio del proceso de sangría.

\section{Proceso de producción de láminas}

Para la producción de las láminas de caucho se adaptó el proceso planteado por la Confederación Cauchera Colombiana (2015a). El látex obtenido de cada tratamiento de preservación se recolectó en recipientes diferentes y se filtró para retirar impurezas. Se tomaron cinco muestras por $100 \mathrm{ml}$ de cada tratamiento de anticoagulación en campo del látex y se evaluó el proceso de dilución en agua con relación a la dilución estándar (un litro de agua por litro de látex) variando la cantidad de agua requerida: D1 (100 \% v/v), D2 $(75 \% \mathrm{v} / \mathrm{v})$, D3 (50 \% v/v), D4 (25 \% v/v), D5 (0 \% v/v) por cuadruplicado. La acidificación se realizó bajo el parámetro de $1 \mathrm{~cm}^{3}$ de ácido fórmico al 90 \% por cada 2 litros de dilución. Al tratar con muestras pequeñas de laminación se adicionó ácido fórmico comercial diluido al $5 \%$ para facilitar su aplicación en dosis pequeñas calculados para cada ensayo de dilución de manera proporcional al parámetro en canoas de prueba de $5 \mathrm{~cm}$ de alto, 10 $\mathrm{cm}$ de largo y $7 \mathrm{~cm}$ de ancho en material aluminio para alimentos, sin adicionar más por la presencia del agente anticoagulante en el látex, asegurando un adecuado mezclado. El tiempo de coagulación fue de 24 h en moldes de aluminio para alimentos, la laminación se realizó con 3 pases y 3 torques en una laminadora artesanal.

Las láminas fueron escurridas por gravedad por un día y se trasladaron para secado en el horno de convección natural en las instalaciones de la Universidad de los Llanos, a una temperatura de $60^{\circ} \mathrm{C}$ hasta obtener peso constante.

\section{Pruebas mecánicas a las láminas de caucho}

Se determinó el espesor final de las láminas por quintuplicado mediante pie de Rey digital de la marca Caliper de 0-150mm. Se realizaron pruebas de tensión con láminas de $7 \mathrm{~cm}$ de largo por $3 \mathrm{~cm}$ de ancho y pruebas de compresión con el espesor obtenido, ejerciendo fuerza manual, utilizando el equipo Penetrómetro digital de la marca Mark-10 series 3, con los husillos gancho y cono respectivamente. Los datos fueron adquiridos por medio del software Mesur gauge Demo del equipo Mark 10 Serie 3 (Mark 10 Team, 2016). Al presentarse una relación directa o inversamente proporcional entre el espesor y las diluciones en cada tratamiento, se realizó una interpolación lineal a 2 mm de espesor.

\section{Análisis estadístico}

El diseño experimental fue de tipo factorial jerárquico balanceado. Los datos obtenidos se analizaron estadísticamente por medio de un análisis de varianza (Anova) y prueba de comparaciones múltiples de Duncan a un nivel de confianza del $95 \%$ utilizando el software Infostat versión libre (Di Rienzo et al. 2001). 


\section{RESULTADOS}

\section{Caracterización del látex}

En la tabla 1 se presentan los resultados de las pruebas establecidas en la ASTM D 1076 de contenido de caucho seco (DRC) y contenido de solidos totales (TSC).

Tabla 1. Análisis de DRC y TSC.

\begin{tabular}{ccc}
\hline TSC & DRC & $\begin{array}{c}\text { Índice de sustancias } \\
\text { diferentes a hidrocarburo } \\
\text { de caucho: DRC-TSC }\end{array}$ \\
\hline $37.1 \% \pm 0.27$ & $34.3 \% \pm 0.19$ & $2.8 \% \pm 0.14$ \\
\hline
\end{tabular}

\section{Anticoagulación en campo}

Los resultados del proceso de anticoagulación en campo se presentan en la tabla 2. La densidad del látex recolectado en cada tratamiento se mantuvo estable mientras que el testigo presentó una disminución, reflejado en la producción de ripio donde presentó la mayor formación. Esto indica que los tratamientos con anticoagulantes presentaron mayor estabilidad.

Tabla 2. Mediciones proceso de anticoagulación en campo.

\begin{tabular}{cccc}
\hline Tratamiento & $\begin{array}{c}\text { Densidad } \\
(\mathbf{g} / \mathbf{m l})\end{array}$ & $\mathbf{p H}$ & $\begin{array}{c}\text { \% de formación } \\
\text { de Ripio }\end{array}$ \\
\hline T0 & $0.97+0.02$ & $6.9+0.1$ & $52 \% \pm 0.25$ \\
T1 & $0.98+0.0$ & $8.5+0.02$ & $14 \% \pm 0.05$ \\
T2 & $0.98+0.0$ & $7.8+0.05$ & $13 \% \pm 0.06$ \\
T3 & $0.98+0.0$ & $8.2+0.03$ & $14 \% \pm 0.06$ \\
\hline
\end{tabular}

\section{Medición de espesor}

Al evaluar los tratamientos de anticoagulación con las diluciones (figura 1), se evidenció un menor espesor de lámina en el tratamiento T3 con D1 $(100 \% \mathrm{v} / \mathrm{v})$ de $1.52 \mathrm{~mm}$, con diferencia significativas con respecto al tratamiento testigo T0 con D1
(100\% v/v) de $1.89 \mathrm{~mm}$. El mayor espesor en la lámina se presentó con el tratamiento T0 con D5 $(0 \% \mathrm{v} / \mathrm{v})$ de 2.45 , mostrando un patrón de incremento del espesor al disminuir las diluciones en cada tratamiento. Sin embargo, no hubo diferencia significativa entre las diluciones D1 a D2 en cada tratamiento.

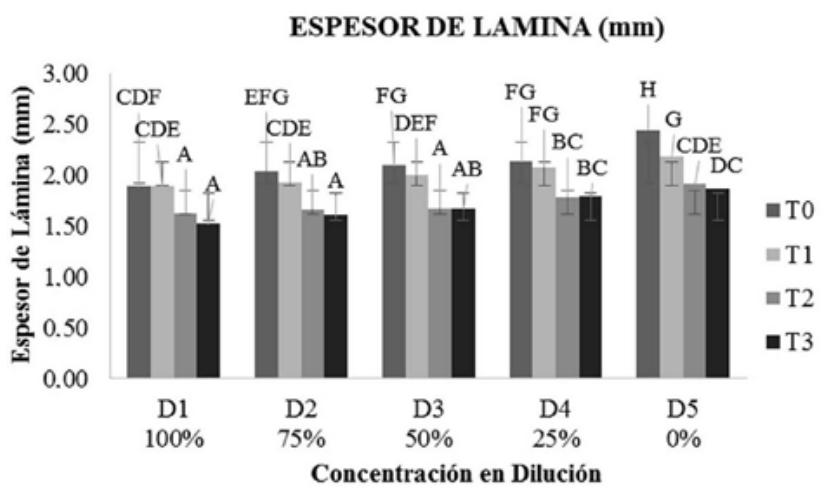

Figura 1. Mediciones de espesor en $(\mathrm{mm})$ de láminas de caucho comparando tratamiento con diluciones; Duncan alfa: 0.05, error: 0.0096, grados de libertad: 57 .

\section{Pruebas mecánicas a las láminas de caucho}

Los tratamientos evidencian una relación inversamente proporcional entre las diluciones y el espesor de las láminas procesadas. Es decir, a medida que disminuye el porcentaje de dilución aumenta el espesor de la lámina. Al no ser estándar el espesor en las láminas de todos los tratamientos y diluciones, se realizó una interpolación lineal a $2 \mathrm{~mm}$ de espesor para determinar el efecto de las pruebas mecánicas.

Al comparar los tratamientos de anticoagulación con las diluciones se evidenció una mayor fuerza de tensión de lámina en el tratamiento T3 con D1 (100\% v/v) de $13.37 \mathrm{KgF}$, con diferencia significativas con respecto al tratamiento testigo T0 con D1 (100 \% v/v) de $11.9 \mathrm{KgF}$, la menor fuerza de tensión en la lámina se presentó con el tratamiento T0 con D5 (0 \% v/v) de $8.51 \mathrm{KgF}$, presentándose un patrón de decrecimiento de la fuerza de tensión al disminuir las diluciones en cada 
tratamiento. Sin embargo, no se presentan diferencias significativas entre las diluciones D1 y D2 de los tratamiento T1 a T3, a diferencias del tratamiento T0, que presentó diferencias significativas en estas diluciones (figura 2).

En la figura 3 se observa el punto de ruptura de las láminas al ejercer una fuerza manual de tensión con el equipo penetrómetro (husillo gancho), registrando los datos digitalmente con el software Mesur gauge Demo del equipo Mark 10 serie 3, obteniendo $10.2 \mathrm{KgF}$, correspondiente al rango del tratamiento T3.

TENSIÓN (KgF)

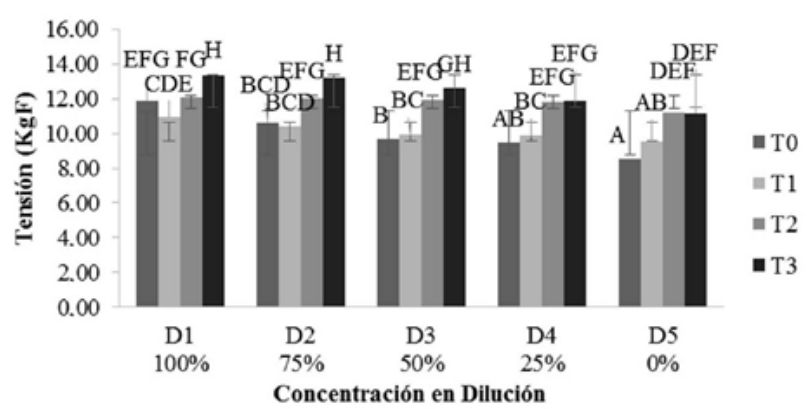

Figura 2. Resultados mediciones de tensión en (KgF) de láminas de caucho comparando tratamiento con diluciones; Duncan Alfa: 0.05 Error: 0.0140 grados de libertad: 57.

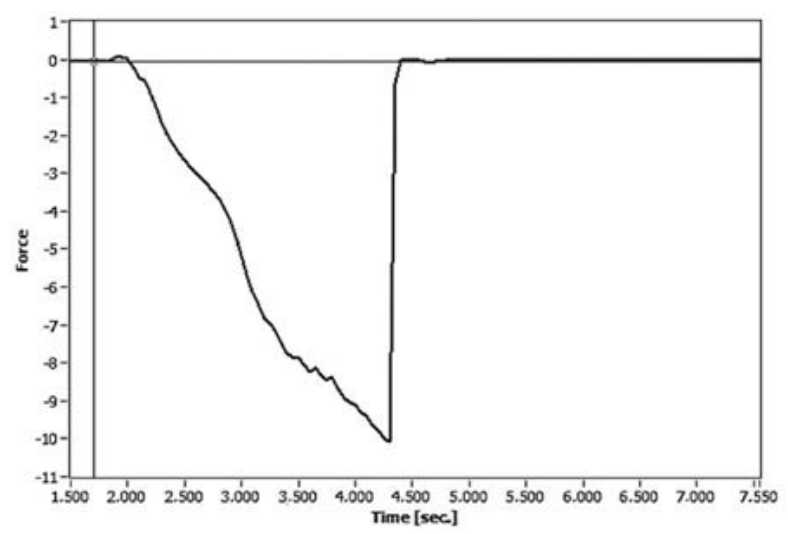

Figura 3. Comportamiento de la tensión de láminas de caucho hasta punto de ruptura en software Mesur gauge Demo del equipo Mark 10 Serie 3 Force (KgF), Time (segundos).
Al comparar los tratamientos de anticoagulación con las diluciones se evidenció una menor resistencia a la compresión de la lámina en el tratamiento T3 con D1 (100 \% v/v) de 5 KgF. La mayor resistencia a la compresión en la lámina se presentó con el tratamiento testigo T0 con D1 (0 \% v/v) de $5.78 \mathrm{KgF}$; T0 con D5 (0 \% v/v) de $6.22 \mathrm{KgF}$ mostró la mayor resistencia a la compresión, evidenciando un patrón de incremento de la resistencia a la compresión al disminuir las diluciones en cada tratamiento. Por otro lado, se encontró que el tratamiento T3 presentó diferencia significativa en

\section{COMPRESIÓN (KgF)}

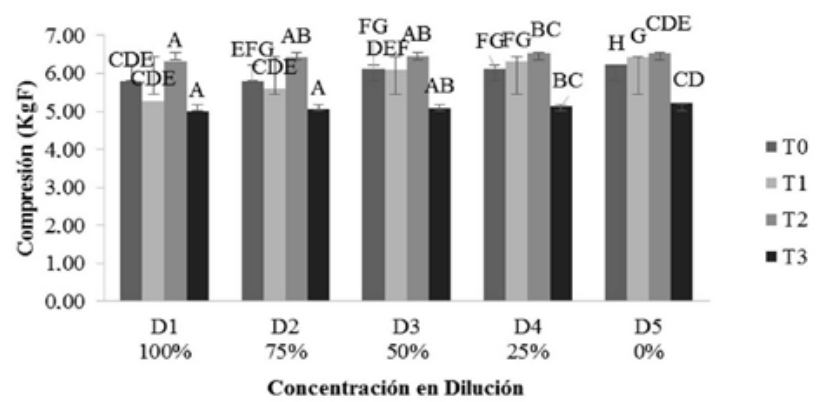

Figura 4. Resultados mediciones de compresión en (KgF) de láminas de caucho comparando tratamiento con diluciones; Duncan Alfa: 0.05 Error: 0.0096 grados de libertad: 57 .

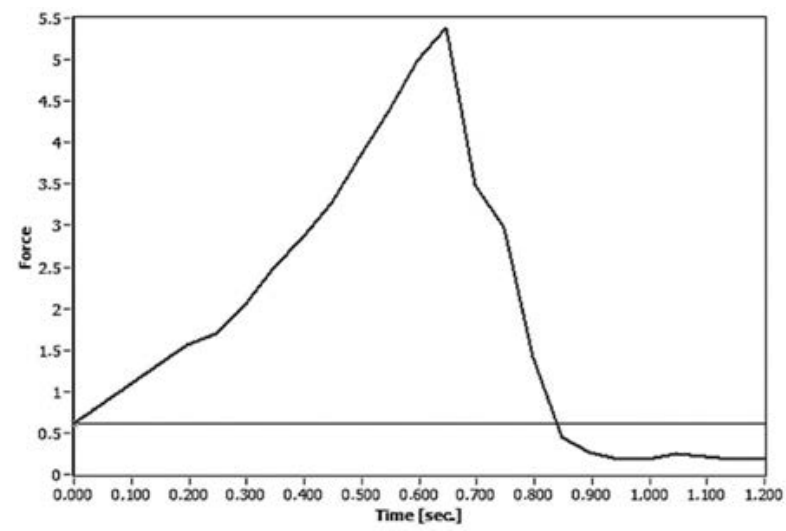

Figura 5. Comportamiento de la compresión de láminas de caucho hasta punto de ruptura en Software Mesur gauge Demo del equipo Mark 10 Serie 3, Force (KgF), Time (segundos). 
todas las diluciones, mientras que los tratamientos T2 a T0 no presentaron diferencias significativas entre las diluciones D1 a D2 (figura 4).

En la figura 5 se observa el punto de ruptura de las láminas al ejercer una fuerza manual de compresión con el equipo penetrómetro (husillo cono) registrando los datos digitalmente con el software Mesur gauge Demo del equipo Mark 10 Serie 3, llegando hasta $5.45 \mathrm{KgF}$, rango del tratamiento T2.

\section{DISCUSIÓN}

\section{Caracterización del látex}

Los resultados obtenidos en la caracterización del látex del clon FX-3864 de seis meses de explotación reflejan un contenido de DRC de $34.3 \% \pm 0.19$ y TSC $37.1 \% \pm 0.27$, con un índice de material diferente al caucho de $2.8 \pm 0.14$. El látex naturalmente presenta variación en su composición coloidal ya sea por factores como condiciones del suelo del cultivo, clima, tiempo de explotación, bacterias y material vegetal empleado que afectan principalmente la composición en cuanto a DRC y TSC. Altos valores de DRC representan mayor productividad en el rendimiento de producción de caucho seco. Sin embargo, también representa un aumento en la viscosidad de la composición coloidal del látex que conlleva al taponamiento del manto laticífero producción obstrucción en la salida del látex del panel de sangría (Jacob et al., 1989). El DRC del látex se encuentra en promedio entre el 27 y el $45 \%$, y el índice de material diferente al caucho ( Diferencia entre el DRC y TSC) se encuentra entre el 3 y 6 \% ( Cáceres \& Gauthler, 2012; Camacho et al., 2014); esto indica que la caracterización realizada se encuentra dentro de los parámetros de composición. En el estudio de caracterización de dos parámetros del látex de clones de Hevea Brasiliensis realizado por Quesada et al. (2012) se evaluaron los clones RRIM 600, IAN 873 y FX 3864 ubicados en la altillanura colombiana, con tres años de explotación. El clon FX 3864 presentó un
TSC de $36.8 \%$ y DRC de $35.6 \%$ con una diferencia de 1.2 , valores similares presentados con el evaluado en esta investigación en el cultivo de seis meses de explotación. Los otros Clones RRIM 600 e IAN 837 presentaron valores de DRC de 42.7 y 41.3, y TSC de 45.5 y 43.8 respectivamente superiores, siendo material vegetal diferente.

\section{Anticoagulación en campo}

En el proceso de campo, la densidad registrada para los tratamientos con anticoagulante T1, T2 y T3 fue de $0.98 \pm 0.0 \mathrm{~g} / \mathrm{cm}^{3}$ tomada durante la recolección, tres horas después de iniciada la sangría, con un $\mathrm{pH}$ de $8.5 \pm 0.02,7.8 \pm 0.05$ y $8.2 \pm 0.03$, respectivamente. Mientras que el tratamiento testigo T0, la densidad disminuyó a $0.97 \pm 0.2 \mathrm{~g} / \mathrm{cm}^{3}$ y $\mathrm{pH}$ de 6.9 \pm 0.1 . La adición de un agente anticoagulante como el amoníaco en el proceso de tapping previene que las bacterias presentes en el panel de sangría acidifiquen el látex, estabilizando la suspensión (Krickl et al., 2017), mientras que el bórax presenta la propiedad preservante evitando la descomposición por bacterias del látex (Confederación Cauchera Colombiana, 2015a). El pH comercial del látex preservado se encuentra alrededor de 10.08 con una densidad de $0.98 \mathrm{~g} / \mathrm{cm}^{3}$ (Parra et al., 2005), siendo evidente que en el tratamiento T0, testigo, inició la coagulación natural del látex que produce al finalizar el proceso de sangría, fondo de taza o ripio de bajo valor comercial que disminuye la producción al no ser incorporar en procesos como laminado o preservación del látex por afectar su calidad (Riyajan \& Santipanusopon, 2010; Tavera et al., 2012; Peláez et al., 2014).

El costo en el mercado de ripio se encuentra alrededor de $\$ 2000 \mathrm{Kg}$ seco, la lámina se encuentra alrededor de $\$ 4000 \mathrm{Kg}$, mientras que el látex esta alrededor de $\$ 1200 \mathrm{Kg}$; con la aplicación de un anticoagulante se redujo en un 38 \% la producción de ripio que tiene un costo de inversión de aplicar $2 \mathrm{~cm}^{3}$ de anticoagulante en taza es de $\$ 8$ pesos con amoníaco, $\$ 1.5$ pesos con bórax y $\$ 5.25$ pesos un combinado de estos anticoagulantes. 
Es decir, si un productor mensualmente recolecta $100 \mathrm{~kg}$ de caucho seco, $38 \%$ adicional se produciría en ripio de 400 árboles con rayado cada cuatro días, siete veces al mes se gastaría $\$ 22$ 400 con el anticoagulante de mayor costo expuesto anteriormente. Venderlo en ripio representaría una ganancia de $\$ 76000$, mientras que venderlo en lámina representaría \$129 600 incluido el costo de la aplicación del anticoagulante, es decir, más del $42 \%$ de recuperación de ganancias, mientras que en látex \$91 600 incluido el costo, es decir el $17 \%$ de recuperación con los precios del mercado actual.

\section{Medición de espesor}

Aunque es muy poca la literatura de investigación en el efecto que se produce al aplicar un agente anticoagulante con la variación de los porcentajes de dilución en el espesor y las propiedades mecánicas de la laminación, los resultados permiten evidenciar un efecto bajo estas circunstancias.

Durante el proceso de producción de láminas de caucho, la adición de un componente ácido permite que las partículas de caucho dispersas en la solución coloidal se agrupen y formen los coágulos de caucho de laminación, siendo entonces la dilución con la adición de agua un factor importante que permite que los componentes no elastómeros se separen y el ácido actué homogéneamente en la formación del coágulo de caucho; el exceso de agua queda atrapado en su interior y es removido junto con los otros componentes (Enciso et al., 2014; Peláez et al., 2014; De oliveira et al., 2015). En primera instancia, teniendo en cuenta los resultados en la figura 1, la variación de la dilución tiene una relación inversamente proporcional con el espesor de las láminas obtenidas. Es decir, a medida que se disminuye el porcentaje de dilución aumenta el espesor manteniendo la igualdad en el tamaño de las canoas de coagulación. La diferencia presentada entre tratamiento puede estar relacionado con la presencia de los cristales de bórax como preservante; los tratamientos T2 y T3 con presencia de este componente presentaron menor espesor en las láminas, lo que indica que existe una relación estructural favorable en las láminas producidas. De acuerdo con Camacho et al. (2014), la presencia de minerales o impurezas afecta las propiedades del caucho; al ser el bórax utilizado como preservante del caucho presenta una compatibilidad que pudo generar enlaces químicos que permitieron que los coágulos de caucho se formaran lentamente sin generar fuertes aglomerados, facilitando la reducción del espesor en el laminado. Sin embargo, no hay diferencia significativa entre las diluciones D1 y D2, lo que permite inferior que se puede reducir este parámetro en un $25 \%$.

\section{Pruebas mecánicas a las láminas de caucho}

Dado que el espesor es un parámetro no controlable por las diferentes diluciones aplicadas, se realizó una interpolación lineal a 2 mm de espesor con cada uno de los resultados de las pruebas mecánicas de tensión y compresión.

La tensión se evaluó sometiendo las láminas de caucho a fuerzas opuestas hasta obtener el punto de ruptura de la lámina y para la compresión se aplicaron fuerzas hacia el centro de la lámina hasta obtener el punto de ruptura. El caucho tiene la particularidad de que al ceder a la fuerza de deformación a la cual está siendo expuesta de forma instantánea y recupera su forma por ser un material elástico (Arguello \& Santos, 2016). Sin embargo, la ley de Hooke no es válida en este tipo de materiales ya que no exhiben una relación lineal entre el esfuerzo y la deformación unitaria, la recuperación no se realiza de la misma trayectoria con la que tuvo la deformación (Hibbeler et al., 2006). De acuerdo con el módulo de Young, para materiales poliméricos no homogéneos, las fuerzas de tensión y compresión no son iguales y la fuerza sobre el objeto es proporcional a su elongación (Young \& Eichhorn, 2007). En la figura 2 se observa la deformación por fuerzas de tensión en la lámina hasta el punto de ruptura, la fuerza de tensión se representa en el plano de manera negativa mientras que 
en la figura 4 la compresión se representa de forma positiva. Al efectuarse el punto de ruptura se termina la fuerza de deformación en la lámina, la cual presenta por sus propiedades elásticas; las partículas tienden a organizarse, volviendo a recuperar su forma inicial (Kane \& Sternheim, 2007). Los resultados de las pruebas mecánicas evidencian que se presenta mayor tensión y menor compresión con el tratamiento T3 combinado entre amoníaco-bórax, sin presentarse diferencia significativas entre las diluciones D1 a D2 (figuras 2 y 4), resultados que evidencian diferencias con el tratamiento testigo T0; la reducción de la compresión representa menor fuerza de extrusión de los equipos en el proceso de transformación industrial, mientras que la tensión evidencia un aumento en la resistencia del punto de ruptura.

Diferentes investigaciones han evaluado el efecto de la adición de partículas sobre las propiedades de los compuestos de caucho natural (NR). Vélez et al. (2016) estudiaron la adición de particulas micrométricas de gilsonita reforzado con N330, comparando el efecto de sistemas de vulcanización convencionales y eficientes; encontraron que la adición de gilsonita facilitaba la incorporación de negro de carbono durante el mezclado, disminuyendo la reversión durante ensayos reométricos de compuestos con sistemas de curado de vulcanización eficaces y aumentando la resistencia dieléctrica. Por otro lado, Flauzino Neto et al. (2016) añadieron nanocristales de celulosa hallando un incremento de la resistencia a la deformación elástica desde 0.19 Mpa (NR) hasta 0.54 Mpa y en la dureza desde 0.59 (NR) hasta $3.03 \mathrm{Mpa}$ cuando hay inclusión del $5 \%$ de nanocristales. Lo que indica que la adición de componentes al caucho representa una variación en las propiedades mecánicas de las láminas.

\section{Aporte ambiental}

En cuanto al beneficio de reducir el consumo de agua, una reducción del 25 \% solo para la producción del departamento del Meta (que se encuentra alrededor de 41 toneladas de lámina al año, que equivalen aproximadamente a 102500 litros de látex al año) equivale a alrededor de 25625 litros de agua. A nivel nacional, donde se producen 570.6 toneladas de lámina al año que equivalen aproximadamente a 1426500 litros de látex al año, se reduciría alrededor de 356625 litros de agua, que no se convertirán en aguas residuales con un pH inferior al 2 por acción de los ácidos utilizados en el proceso, y que por esta condición genera acidificación de las fuentes hídricas y los suelos si no se realiza tratamiento (Kornochalert et al., 2014).

\section{CONCLUSIONES}

Las interacciones realizadas con la aplicación de anticoagulantes en campo y la variación de la dilución en el proceso de laminado permitieron concluir que existe una mayor resistencia de tensión hasta punto de ruptura de $13.37 \mathrm{KgF}$, compresión de $5 \mathrm{KgF}$ y menor espesor de $1.52 \mathrm{~mm}$ con el tratamiento T3D1. Sin embargo, estadísticamente no hay diferencia significativa entre los tratamientos T3 y T2, con una reducción de formación de ripio del $38 \%$, y las diluciones D1 y D2, con una reducción del consumo de agua del $25 \%$, demostrando la importancia en el estudio de la inclusión de anticoagulantes no solo para la reducción del consumo de agua durante el procesamiento, también para evitar reprocesos asociados a la contaminación de las láminas ocasionadas por la coagulación en campo.

\section{AGRADECIMIENTOS}

Los autores agradecen al Fondo Social de Educación Superior del Meta (FSES) y a la Gobernación del Meta, en el marco del proyecto "Fortalecimiento de las capacidades de investigación en ciencia y tecnología e innovación del departamento del Meta 2015", a través del apoyo de créditos- beca-pasantía para jóvenes investigadores. 


\section{CONFLICTO DE INTERESES}

Los autores declaran no tener conflicto de intereses.

\section{CONTRIBUCIÓN POR AUTOR}

El autor único es responsable de la obra en todos los aspectos que condujeron a la elaboración de su publicación.

\section{REFERENCIAS BIBLIOGRÁFICAS}

Arguello, J.M., \& Santos, A. (2016). Hardness and compression resistance of natural rubber and synthetic rubber mixtures. Journal of Physics: Conference Series 687(1), 012088. DOI: https://doi. org/10.1088/1742-6596/687/1/012088

Cáceres Sandoval, A.P., \& Gauthler Maradei, P. (2012). Análisis termogravimétrico como un nuevo método para la determinación de contenido de sólidos totales (CST) y caucho seco (CCS) del látex natural. ION, 25(2), 57-65.

Camacho Támara, A. M., Reyes Pineda, H., \& Lozano Bohórquez, A. (2014). Análisis y caracterización fisicoquímica del látex de caucho especie Hevea Brasiliensis. Tumbaga, 1(9), 83-97.

Confederación Cauchera Colombiana. (2015a). Manual práctico para el rayado de árboles de cacucho. Bogotá: Confederación Cauchera Colombiana. 35 p.

Confederación Cauchera Colombiana. (2015b). Informe de resultados, censo de plantaciones de caucho natural (Hevea brasiliensis). Bogotá: Confederación Cauchera Colombiana. 30 p.

Cornish, K., Xie, W., Williams, J., Nguyen, K., \& Kostyal, D. (1988). ASTM D 1076 Standard specification of rubber-concentrated, ammonia preserved, creamed and centrifuged natural latex. Philadelfia: International Standards Worldwide. 9 p.

De Oliveira Reis, G., Menut, P., Bonfils, F., Vaysse, L., Hemar, Y., \& Sanchez, C. (2015). Acid-induced aggregation and gelation of natural rubber latex particles. Colloids and Surfaces A: Physicochemical and
Engineering Aspects, 482, 9-17. DOI: https://doi.org/10.1016/j.colsurfa.2015.04.015

Departamento nacional de planeación (DNP). (2007). Agenda interna para la productividad y la competitividad amazorinoquia. Bogotá: DNP. 80 p.

Di Rienzo, J., Balzarini, M., Gonzalez, L., Casanoves, F., Tablada, M., \& Robledo, C. (2001). Software Estadistico Infostat. Córdoba, Argentina: Universidad Nacional de Córdoba. Recuperado de: https:// www.Infostat.com.ar.

Enciso, J. L., Llano, J. F., Graciano, N., \& Olaya, C. (2014). Diseño y construcción de un prototipo tren de laminación y caracterización de láminas de látex. Revista Colombiana de Materiales, 5, 86-92.

Flauzino Neto, W. P., Mariano, M., da Silva, I. S. V., Silvério, H. A., Putaux, J.-L., Otaguro, H., \& Dufresne, A. (2016). Mechanical properties of natural rubber nanocomposites reinforced with high aspect ratio cellulose nanocrystals isolated from soy hulls. Carbohydrate Polymers, 153, 143-152. DOI: https://doi.org/10.1016/j.carbpol.2016.07.073

Floriano, J. F., da Mota, L. S. L. S., Furtado, E. L., Rossetto, V. J. V., \& Graeff, C. F. (2014). Biocompatibility studies of natural rubber latex from different tree clones and collection methods. Journal of Materials Science: Materials in Medicine, 25(2), 461-470. DOI: https://doi.org/10.1007/s10856-013-5089-9

George, N. A., Peethan, A., \& Vijayan, M. (2013). A simple optical sensor for the measurement of dry rubber content in natural rubber latex. Nondestructive Testing and Evaluation, 28(4), 313-320. DOI: https://doi.org/10.1080/10589759.2013.785545

Hibbeler, R.C. (2006). Mecánica de materiales. México D.F.: Pearson Educación. 896p.

Jacob, J., Prevot, J., Roussel, D., Lacrotte, R., Serres, E., D’Auzac, J., Eschbach, J., \& Omont, H. (1989). Yield limiting factors, latex physiological parameters, latex diagnosis and clonal typology. En J. D'Auzac, J. Jacob \& H. Chrestin (eds.), Physiology of rubber tree latex (pp. 346-381). Boca Raton, FL: CRC Press.

Kane, J.W., \& Sternheim M.M. (2007). Física. Amherts, Massachusetts: Reverte S.A. 795p. 
Kornochalert, N., Kantachote, D., Chaiprapat, S., \& Techkarnjanaruk, S. (2014). Bioaugmentation of latex rubber sheet wastewater treatment with stimulated indigenous purple nonsulfur bacteria by fermented pineapple extract. Electronic Journal of Biotechnology, 17(4), 174-182. DOI: https://doi.org/10.1016/j.ejbt.2014.06.003

Krickl, S., Touraud, D., \& Kunz, W. (2017). Investigation of ethanolamine stabilized natural rubber latex from Taraxacum kok-saghyz and from Hevea brasiliensis using zeta-potential and dynamic light scattering measurements. Industrial Crops and Products, 103(1), 169-174. DOI: https://doi.org/10.1016/j.indcrop.2017.03.046

Mark 10 Team. (2016). Mesur gauge Demo Mark 10 Series 3. EE. UU.: Mark 10 Corporation. Recuperado de: www.mark-10.com.

Nawamawat, K., Sakdapipanich, J.T., Ho, C.C., Ma, Y., Song, J., \& Vancso, J.G. (2011). Surface nanostructure of Hevea brasiliensis natural rubber latex particles. Colloids and Surfaces A: Physicochemical and Engineering Aspects, 390(1), 157-166. DOI: https:// doi.org/10.1016/j.colsurfa.2011.09.021

Parra, D.F., Martins, C.F.P., Collantes, C.H., \& Lugao, A.B. (2005). Extractable proteins from field radiation vulcanized natural rubber latex. Nuclear Instruments and Methods in Physics Research Section B: Beam Interactions with Materials and Atoms, 236(1), 508-512. DOI: https://doi.org/10.1016/j. nimb.2005.04.028

Peláez, G.J., Velásquez , S.M., \& Giraldo, D.H. (2014). Aditivos para el procesamiento del caucho natural y su aplicación en pequeñas plantaciones de caucho. Informador Técnico (Colombia), 78(2), 166-174.

Quesada, I., Aristizábal, F., \& Montoya, D. (2012). Caracterización de dos parámetros del látex de clones de Hevea brasiliensis (Willd. ex A. Juss.) Mull. Arg. En la altillanura Colombiana. Colombia Forestal, 15(1), 139-146. DOI: https://doi.org/10.14483/ udistrital.jour.colomb.for.2012.1.a06

Rayas, J., Rodríguez Vera, R., \& Martínez, A. (2003). Medición del módulo de Young en el hule látex usado ESPI. Mexicana de Física, 49(6), 555-564.

Riyajan, S.A., \& Santipanusopon, S. (2010). Influence of ammonia concentration and storage period on properties field NR latex and skim coagulation. KGK. Kautschuk, Gummi, Kunststoffe, 63(6), 240-245.

Tamara, A.M.C., Pineda, H.R., \& Bohórquez, A.L. (2015). Análisis y caracterización fisicoquímica del látex de caucho especie Hevea brasiliensis. Revista Tumbaga, 1(9), 83-97.

Tavera, C.P., \& Gauthier, P. (2012). Estudio experimental de las etapas de cremado y separación de un proceso de producción de látex natural cremado. ION, 25(1), 7-15.

Vélez, J.S., Velásquez, S., \& Giraldo, D. (2016). Mechanical and rheometric properties of gilsonite/carbon black/natural rubber compounds cured using conventional and efficient vulcanization systems. Polymer Testing, 56(1), 1-9. DOI: https://doi.org/10.1016/j.polymertesting.2016.09.005

Young, R.J., \& Eichhorn, S.J. (2007). Deformation mechanisms in polymer fibres and nanocomposites. Polymer, 48(1), 2-18. DOI: https://doi.org/10.1016/j.polymer.2006.11.016

Zuhainis, S.W., Hassan, A.A., Singh, M., \& Mohamad, R. (2015). Microbial Surfactant for Preservation of Natural Rubber Latex. Beneficial Microorganisms in Agriculture, Aquaculture and Other Areas, 29 (1), 101-128. DOI: https://doi. org/10.1007/978-3-319-23183-9_6 